Article

\title{
Numerical Analysis on the Radiation-Convection Coupled Heat Transfer in an Open-Cell Foam Filled Annulus
}

\author{
Xue Chen ${ }^{1,2}$, Chuang Sun ${ }^{2, *}$, Xinlin Xia ${ }^{2}$ and Rongqiang Liu ${ }^{1}$ \\ 1 School of Mechatronics Engineering, Harbin Institute of Technology, 92, West Dazhi Street, \\ Harbin 150001, China; hit_chenxue@hit.edu.cn (X.C.); chenxuehit@gmail.com (R.L.) \\ 2 School of Energy Science and Engineering, Harbin Institute of Technology, 92, West Dazhi Street, \\ Harbin 150001, China; xiaxl@hit.edu.cn \\ * Correspondence: sunc@hit.edu.cn; Tel.: +86-0451-8641-2148
}

Received: 28 September 2018; Accepted: 8 October 2018; Published: 11 October 2018

\begin{abstract}
Forced flow and radiation-convection coupled heat transfer in an annulus filled with open-cell foam was numerically investigated at high temperatures. The Darcy-Brinkman-Forchheimer model was utilized to represent the fluid transport. The two-energy equation model was applied for the non-equilibrium heat exchange between the fluid and solid phases, while the radiation heat transfer within the foam material was solved using the P1 approximation. Two different cases of thermal boundary conditions were studied and discussed in detail, namely the inner wall with a constant heat flux while the outer wall was adiabatic (case I) and vice versa (case II). The effects of pertinent factors on the heat transfer characteristics were examined, such as the foam structural parameters and the radii ratio of the annulus. The temperature, local and average Nusselt number were predicted. The results indicate that neglecting the thermal radiation causes a large deviation in predicting the thermal performance of such foam-fluid systems. Increasing the porosity and pore diameter both promote the radiation heat transfer, while it is weakened by increasing the radii ratio. The average Nusselt number decreases as the porosity increases, while it exhibits a non-monotonic change with the pore diameter and radii ratio. Besides, case I shows a higher average Nusselt number than case II and presents an improved thermal performance.
\end{abstract}

Keywords: open-cell foam-filled annulus; radiation-convection heat transfer; local thermal non-equilibrium; high temperature

\section{Introduction}

Holding the structural and functional features, the reticulated open-cell foams exhibit a favorable performance in various engineering applications. Due to the tortuous microstructure and the high surface area density, the foams are regarded as a promising material for augmenting heat transfer. The flow and heat transport inside the open-cell foam have great practical interests in many thermal systems, especially under high-temperature conditions, such as solar receivers [1], thermochemical reactors [2], porous radiant burners [3], and melt filters [4].

So far, the flow and thermal characteristics inside the foam materials have been extensively investigated. Nevertheless, the extreme randomness of foam structure has greatly limited the design optimization through experimental tests [5]. In the numerical predictions, a macroscopic approach, based on the volume averaging technique (VAT), is widely used. This approach is to solve the volume-averaged governing equations and considers the fluid and solid phases as equivalent continuous media [6]. The two distinctive models, the local thermal equilibrium (LTE) model and the local thermal non-equilibrium (LTNE) model, are frequently used to characterize the heat exchange between the fluid and solid matrix. 
Moreover, taking the temperature difference between the two phases into account, the LTNE model has been demonstrated to be more adequate and reliable [7-10]. The promotion in the thermal performance of a compact heat exchanger with a foam insert has been reported in comparison with an identical heat exchanger with no foam or even other surface extension techniques. A large amount of information can be found in the literature addressing fully or partially filled foam tubes and channels [11,12], foam wrapped tubes [13], foam fins [14] and other configurations. Among these, the annular duct is a commonly used configuration in heat exchangers, thermal storage devices, and heat sinks $[15,16]$, and some investigations on the thermal performance of these devices with porous inserts have also been performed, without considering the radiation heat transfer.

Several investigations have been conducted on the convection heat transfer in a cylindrical annulus occupied by porous material using the LTE model. Considering the wall effects, Cheng and Hsu [17] presented an analysis of the forced convection in a packed-sphere bed within concentric annular cylinders at different temperatures. Analytical results were derived by Chikh [18] for the convection inside an annular duct, which was partially occupied with porous media, while the inner wall was subjected to a constant heat flux and the outer wall was well insulated. Experimental tests were performed by Noh [19] to study the flow and thermal transport within an annulus with aluminum foam and new empirical expressions for the Nusselt number and friction factor were established. The entropy generation in a porous annulus heat exchanger was analyzed by Chikh and Allouache [20] to find an optimal porous layer thickness. A thermally developing flow inside an elliptic annulus with a metal foam was analytically and numerically investigated by Benmerkhi [21] using the LTE model. A sensitivity analysis was carried out by Milani Shirvan [22] to study the thermal performance of a porous double-pipe heat exchanger with the LTE model.

Considering the temperature difference between the fluid and solid matrix, only a few studies have been done on the forced convection inside an open-cell foam filled annulus. Using the LTNE model, the transient non-thermal equilibrium heat transfer between the two phases was studied by Kuznetsov [23] for a concentric porous annulus at a constant wall temperature. The thermal performance of a tube-in-tube heat exchanger with a metal foam insert under the counter-flow arrangement was analyzed by Zhao [24] with a prescribed heat flux on the interface wall. With the thermal boundaries of heat flux at the inner cylinder and an adiabatic outer cylinder, the forced convection heat transfer in a foam-air annulus was studied by Yang [25]. The flow and heat transfer within a partly filling foam annulus were theoretically investigated by Qu [26]. A theoretical investigation was carried out by Wang [27] for a micro-annulus with a porous insert under two distinctive cases using the LTNE model. Besides, the analytical solutions for convection in a porous annulus, subjected to asymmetrical heating, were developed by Xu [28,29], considering the effects of slip and no-slip conditions. The forced convection through a vertical annulus filled with a foam material was analyzed by Orihuela [30] experimentally and numerically.

From a literature survey, the prior work has mainly focused on the convection heat transfer within the foam filled annulus, while neglecting the thermal radiation, which may dominate the heat transfer at a high temperature. With increasing high-temperature applications [31-33], the radiation-convection coupled heat transfer behavior in such foam-fluid systems should be comprehensively studied. To the authors' best knowledge, the high-temperature coupled heat transfer in an open-cell foam filled annulus has not been reported in the literature. In this study, the main objective was to build a numerical model to investigate the heat transfer behavior of such thermal systems and to further discuss the effects of pertinent design parameters under two typical cases of thermal boundary conditions. The results provide a reference for the design of such foam-fluid heat exchangers at a high temperature.

\section{Problem Statement}

Figure 1 presents the schematic of the physical problem in this work. The annulus was completely filled with open-cell foam in order to intensify the heat transfer. The radii of the inner and outer concentric cylinders are $R_{1}$ and $R_{2}$ respectively, while the length is $L$. Two typical thermal boundary 
conditions were imposed on the inner and outer walls, namely a constant heat flux and thermal insulation, while two cases were taken into consideration here (see Figure 1). In order to keep the same total imposed heat load and to make a direct comparison between the two cases, the heat fluxes follow the correlation $q_{w 2}=q_{w 1} R_{1} / R_{2}$. The fluid flow was laminar, steady and incompressible. At the entrance, the fluid had a uniform velocity and temperature. The foam material was regarded as gray, absorbing, emitting, and isotropically scattering homogeneous media. Additionally, the fluid (air) was completely transparent to thermal radiation.
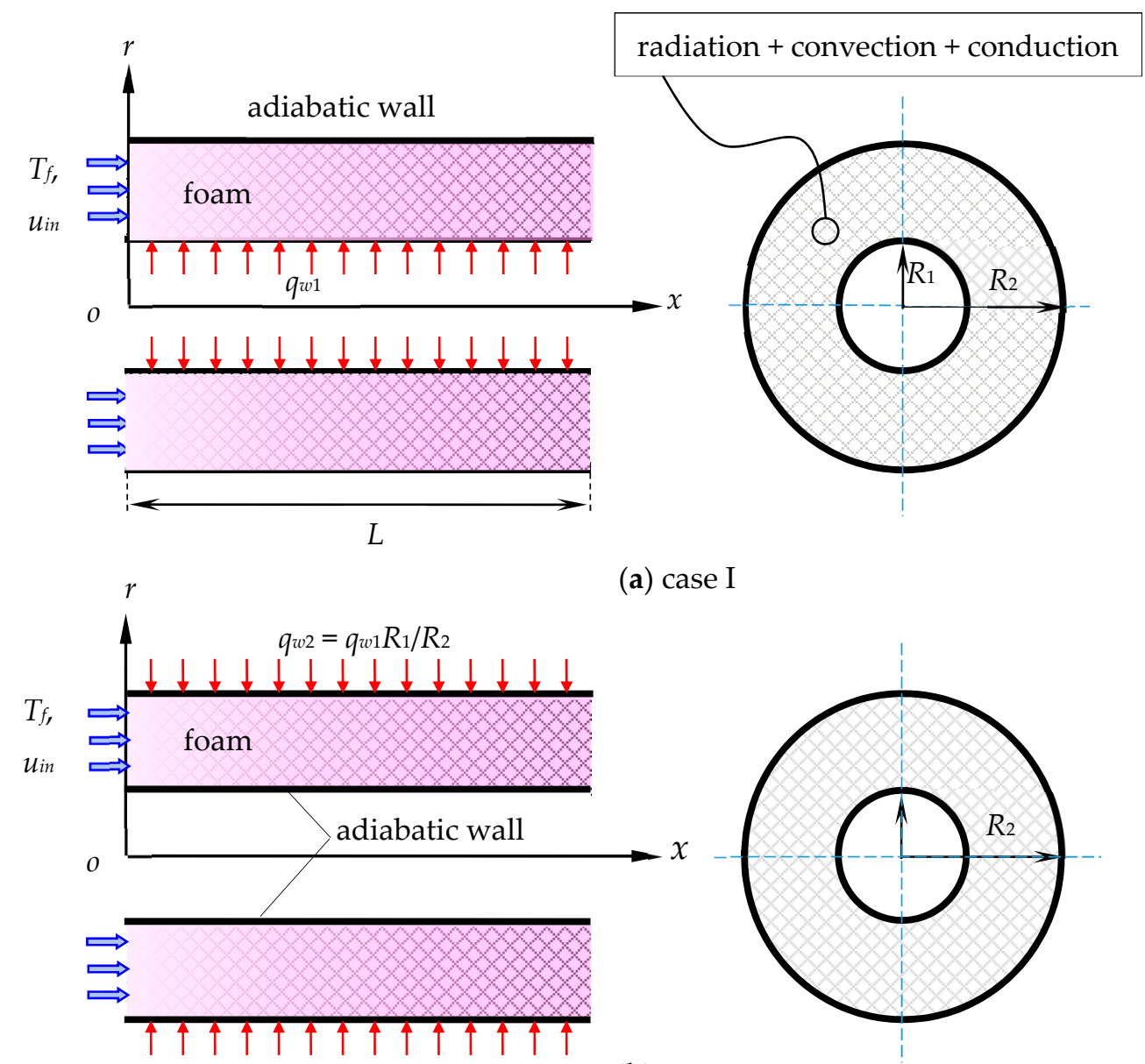

(b) case II

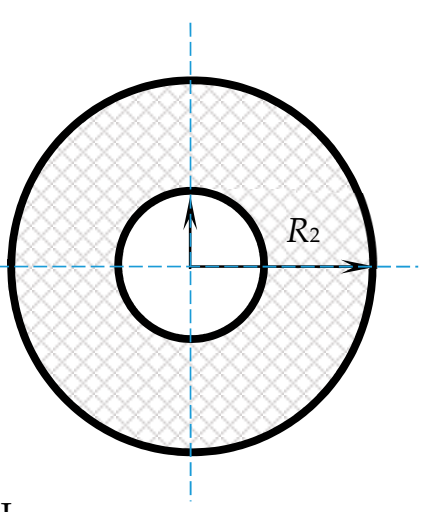

Figure 1. Schematic diagram of an annulus with a foam material insert, (a) case I: Constant heat flux at the inner wall and (b) case II: Constant heat flux at the outer wall.

\section{Governing Equations}

The Darcy-Brinkman-Forchheimer formulation was utilized to describe the forced fluid flow through the foam region. The mass and momentum equations for the fluid phase can be expressed as

$$
\begin{gathered}
\nabla \cdot\left(\rho_{f} \boldsymbol{u}\right)=0 \\
\frac{1}{\phi} \nabla\left(\rho_{f} \frac{\boldsymbol{u} \cdot \boldsymbol{u}}{\phi}\right)=-\nabla p+\nabla \cdot\left(\frac{\mu_{f}}{\phi} \nabla \boldsymbol{u}\right)-\frac{\mu_{f}}{K} \boldsymbol{u}-\frac{\rho_{f} C_{F}}{\sqrt{K}}|\boldsymbol{u}| \boldsymbol{u}
\end{gathered}
$$

where $\rho_{f}$ and $\mu_{f}$ are the fluid density and the dynamic viscosity respectively; $\boldsymbol{u}$ denotes the superficial velocity; $\boldsymbol{S}_{m}=-\frac{\mu_{f}}{K} \boldsymbol{u}-\frac{\rho_{f} C_{F}}{\sqrt{K}}|\boldsymbol{u}| \boldsymbol{u}$ is the source term due to the fluid flow across the random porous microstructure, which consists of the viscous and inertia effects; $K$ and $C_{F}$ are the permeability and Forchheimer coefficients respectively; $\phi$ denotes the porosity and $p$ is the fluid pressure. 
The two energy equation model (known as the LTNE model) was used here for the heat transport simulation inside the foam material. The governing equations were built for the fluid phase and the solid phase. Each equation included an interactive term to elucidate the effect of interfacial heat exchange between the two phases. The energy equations were given as

$$
\begin{gathered}
\nabla \cdot\left(\rho_{f} \mathcal{C}_{p} \boldsymbol{u} T_{f}\right)=\nabla \cdot\left(\lambda_{f e} \nabla T_{f}\right)+h_{v}\left(T_{s}-T_{f}\right) \\
\nabla \cdot\left(\lambda_{s e} \nabla T_{s}\right)+h_{v}\left(T_{f}-T_{s}\right)-\nabla \cdot \boldsymbol{q}_{r}=0
\end{gathered}
$$

where $T_{f}, T_{s}, \lambda_{f e}$ and $\lambda_{s e}$ represent the temperatures and the effective thermal conductivities of the two phases, $\lambda_{f e}=\phi \lambda_{f}, \lambda_{s e}=\frac{1}{3}(1-\phi) \lambda_{s}$ [34]; $S_{r}=-\nabla \cdot \boldsymbol{q}_{r}$ is the source term for the effect of the radiation heat transfer; $c_{p}$ is the thermal capacity of the fluid and $h_{v}$ denotes the volumetric heat transfer coefficient, which is utilized to couple the two energy equations. The following correlations were used to determine the momentum source term and volumetric heat transfer coefficient [2].

$$
\begin{aligned}
& S_{m}=-\frac{44.5}{\phi d_{p}^{2}} \mu_{f} \boldsymbol{u}-\frac{0.55}{\phi^{2} d_{p}} \rho_{f}|\boldsymbol{u}| \boldsymbol{u} \\
& h_{v}=0.34 \phi^{-2} \operatorname{Re}_{d}^{0.61} \operatorname{Pr}^{1 / 3} \lambda_{f} / d_{p}^{2}
\end{aligned}
$$

where $d_{p}$ is the mean pore diameter and the Reynolds number is defined as $\operatorname{Re}_{d}=\rho_{f} u d_{p} / \mu_{f}$.

The P1 approximation was employed to simulate the radiation transport inside the porous foam, as it is an effective approach that is less time consuming and provides high accuracy $[35,36]$. For an isotropic scattering medium, the governing equation of the incident radiation, $G$, was expressed as [37]

$$
\begin{gathered}
\nabla \cdot\left(\frac{1}{3 \beta} \nabla G\right)+\kappa\left(4 \sigma T_{s}^{4}-G\right)=0 \\
G=\int_{4 \pi} I(r, s) d \Omega
\end{gathered}
$$

where $\kappa$ and $\beta$ are the absorption coefficient and extinction coefficient for infrared radiation respectively and $I$ is the radiative intensity. Therefore, the source term produced by thermal radiation in the foam material can be determined as $S_{r}=-\nabla \cdot \boldsymbol{q}_{r}=-\kappa\left(4 \sigma T_{s}^{4}-G\right)$. Additionally, the radiation transport properties were computed as [6]

$$
\kappa=\frac{3 \varepsilon(1-\phi)}{2 d_{p}}, \quad \beta=\frac{3(1-\phi)}{d_{p}} .
$$

A prescribed uniform velocity and temperature, $u=u_{\text {in }}$ and $T_{f}=T_{f, i n}$, were imposed at the entrance and the outlet boundary condition was defined with a static pressure of $p=p_{a t m}$ and $\partial T / \partial \boldsymbol{n}=0$. The cylinder walls were assumed to be grey and diffuse and the Marshak's condition was used for the radiation transfer equation. The thermal boundary condition for the heating wall was given as follows [38]

$$
\begin{array}{cl}
\text { case I : } \lambda_{f e} \frac{\partial T_{f}}{\partial r}+\lambda_{s e} \frac{\partial T_{s}}{\partial r}+q_{r}=-q_{w 1}, & T_{f}=T_{s}=T_{w} \\
\text { case II }: \lambda_{f e} \frac{\partial T_{f}}{\partial r}+\lambda_{s e} \frac{\partial T_{s}}{\partial r}+q_{r}=q_{w 2}, & T_{f}=T_{s}=T_{w} .
\end{array}
$$

In addition, the air was treated as an ideal gas, whereas the viscosity, thermal capacity, and thermal conductivity were determined using temperature-dependent functions [39]. The dynamic viscosity was computed using Sutherland's law and the others were calculated by the following formulae

$$
c_{p}=1.93 \times 10^{-10} T_{f}^{4}-8 \times 10^{-7} T_{f}^{3}+1.14 \times 10^{-3} T_{f}^{2}-4.49 \times 10^{-1} T_{f}+1.06 \times 10^{3}
$$




$$
\lambda_{f}=1.52 \times 10^{-11} T_{f}^{3}-4.86 \times 10^{-8} T_{f}^{2}+1.02 \times 10^{-4} T_{f}-3.93 \times 10^{-3} .
$$

Due to the large thermal conductivity and high thermal-shock resistance, $\mathrm{SiC}$ was chosen as the foam solid phase, with a thermal capacity of $750 \mathrm{~J} /(\mathrm{kg} \cdot \mathrm{K})$, a density of $3210 \mathrm{~kg} / \mathrm{m}^{3}$, an emissivity of 0.9 , and a temperature-dependent thermal conductivity, which was determined as [40]

$$
\lambda_{s}=\frac{52000 \exp \left[-1.24 \times 10^{-5}\left(T_{s}-273\right)\right]}{T_{s}+164} .
$$

\section{Numerical Solution and Validation}

The 3D continuity, momentum, and energy governing equations were solved using the software ANSYS FLUENT 16.0 with a finite volume method. Several user-defined functions (UDFs) were programmed to determine the transport parameters and the source terms. The SIMPLE algorithm was adopted to couple the pressure and velocity. The P1 approximation simulation was executed by building a user-defined scalar (UDS) equation. A second-order upwind scheme was used in the solution of momentum and P1 equations, while the QUICK was applied for the energy equation discretization. Uniform grids along the circular and axial directions were used, while non-uniform grids in the radial direction with refinement near the annulus walls were used, as depicted in Figure 2. A grid size of $r \times$ $\theta \times x=50 \times 120 \times 200$ was used after the grid dependence check. Besides, the convergence criteria were set to $10^{-8}$ for all of the equations.

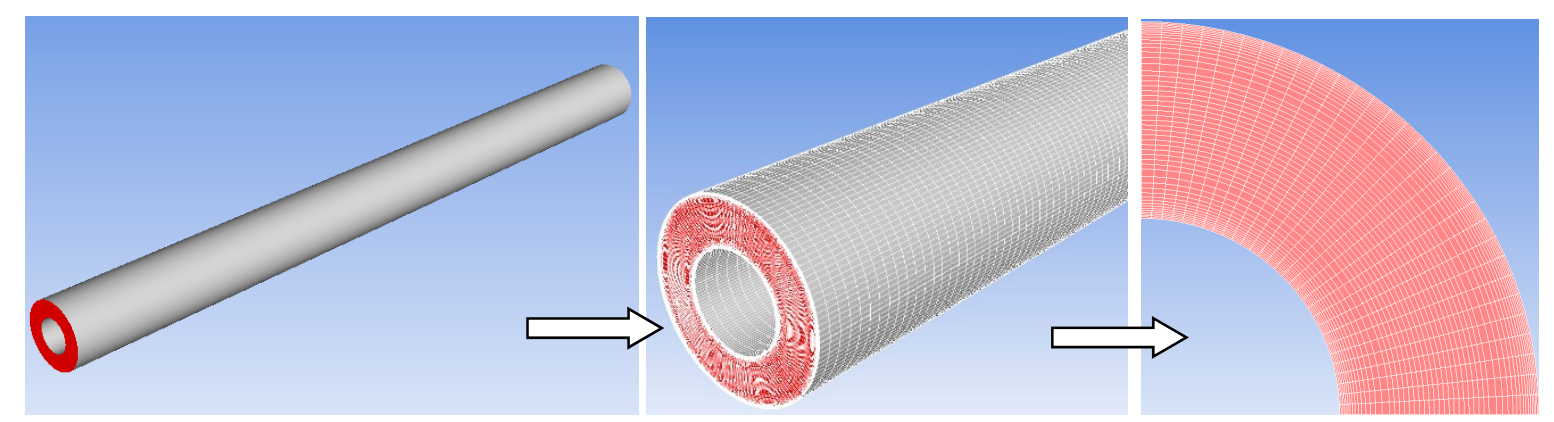

Figure 2. Numerical grids used for the coupled heat transfer simulation in the foam filled annulus.

The source term from the radiation heat transfer in the solid phase energy equation was calculated by UDFs through solving Equation (7). The codes and numerical procedure using the P1 approximation have already been validated at elevated temperatures in Reference [2]. To avoid duplication, the comparison was not repeated here. Additionally, the methods to deal with the boundary condition of constant heat flux at the wall and the LTNE heat exchange between the fluid and solid phases were checked against the data from Reference [26] for the convention in a foam filled annulus $\left(R_{1}=0.01 \mathrm{~m}, R_{2}=0.03 \mathrm{~m}\right)$, where the thermal radiation was disregarded. The thermal boundary condition of case I, in Figure 1, was used, as well as the same parametric conditions and material properties. It can be clearly seen in Figure 3 that the results of the velocity and temperature distributions along the radial direction show satisfactory agreements. In the figure, the dimensionless variables are defined as $\eta=\frac{r-R_{1}}{R_{2}-R_{1}}, \operatorname{Re}=\frac{\rho_{f} u_{i n} \cdot 2\left(R_{2}-R_{1}\right)}{\mu_{f}}, U=\frac{u}{u_{i n}}$ and $\Theta=\frac{T-T_{w 1}}{q_{w 1} R_{1} / \lambda_{s e}}$. 

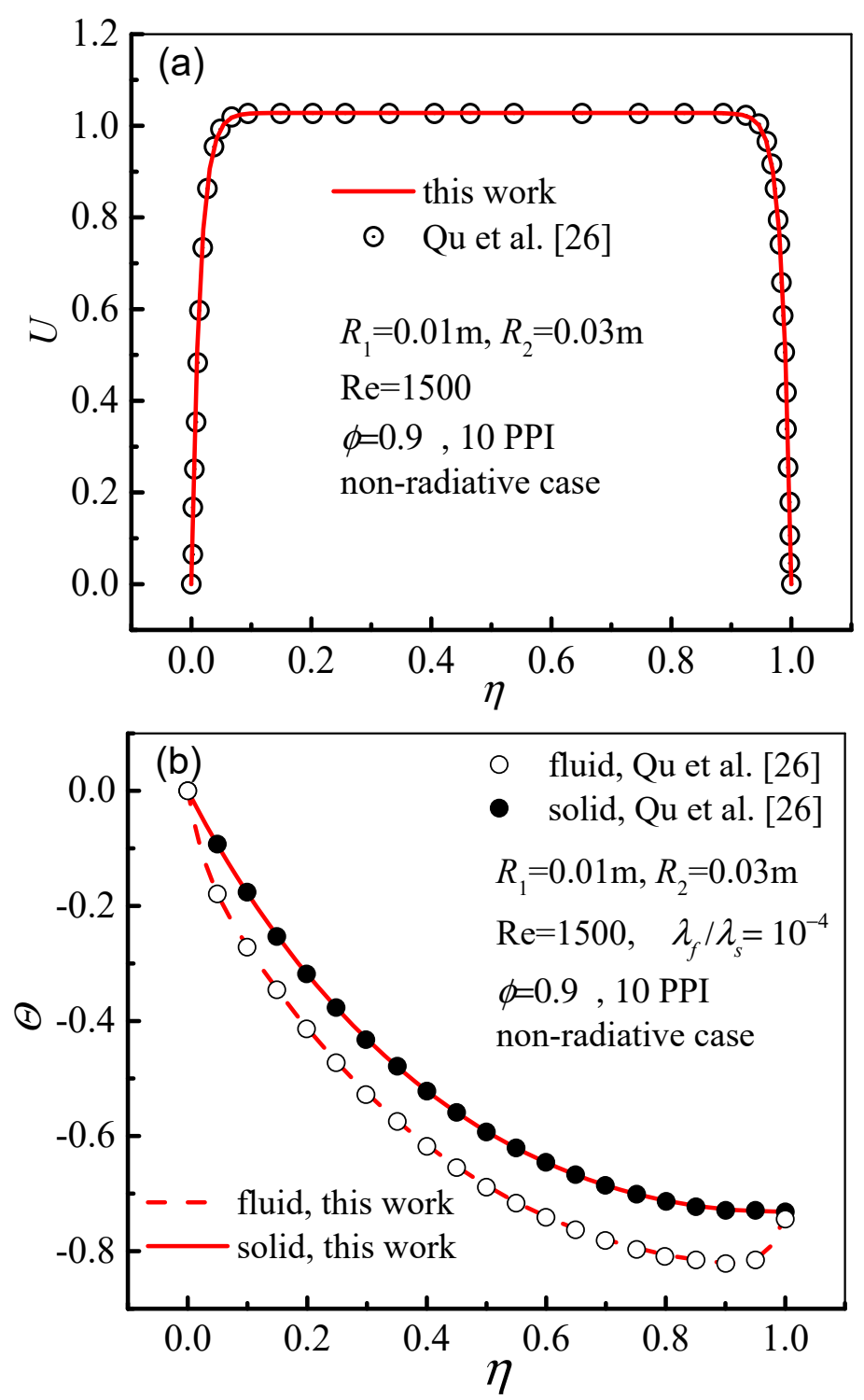

Figure 3. Comparison of the velocity profile (a) and the temperature profile (b) between results calculated in this work and those in Reference [26].

Another validation check was performed for the heat transfer in a foam filled channel with one side uniformly heated, which was experimentally tested by Calmidi and Mahajan [41] and the thermal radiation was also ignored. The Nusselt number is defined as $N u_{0}=\frac{\bar{h} L}{\lambda_{e}}=\frac{q_{w} L}{\lambda_{e}\left(T_{w w}-T_{f, i n}\right)}$, where $\lambda_{e}=\lambda_{f e}+\lambda_{s e}$ is the effective thermal conductivity and $\overline{T_{w}}$ is the average temperature of the heating wall. The operating conditions and transport parameters are directly given in Reference [41]. The variation of the Nusselt number along with the Reynolds number, $\operatorname{Re}_{K}=\rho_{f} u_{\text {in }} \sqrt{K} / \mu_{f}$, is exhibited in Figure 4, which shows good agreement between the prediction in this work and the experiment in Reference [41]. 


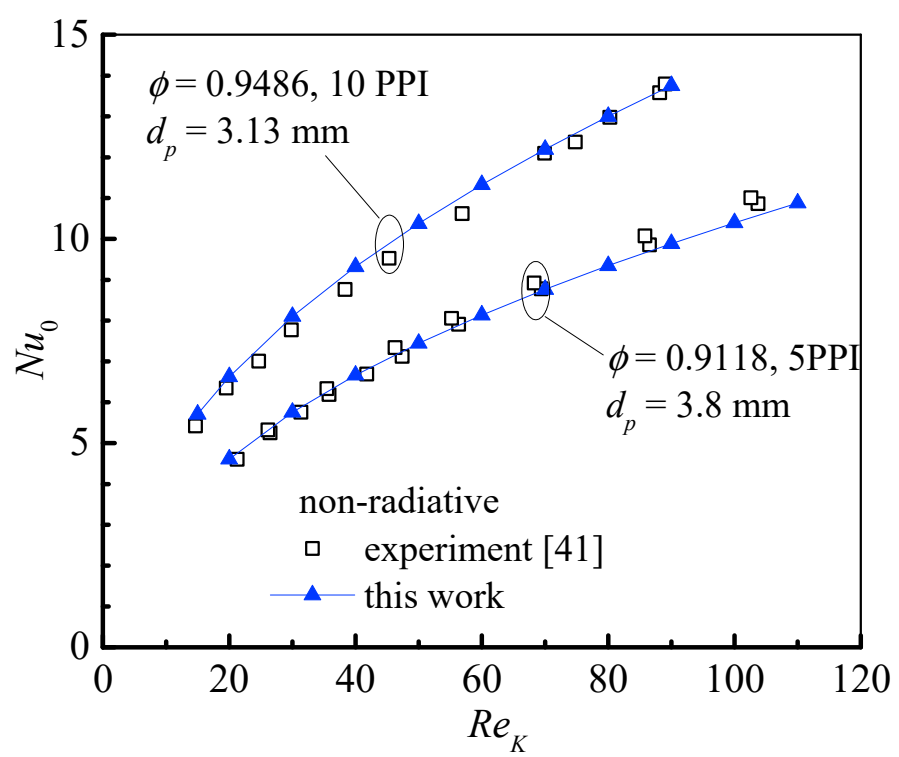

Figure 4. Comparison between the simulation in this work with the experiment in Reference [41].

\section{Results and Discussion}

The geometrical dimensions of the foam filled annulus were $R_{1}=0.02 \mathrm{~m}, R_{2}=0.04 \mathrm{~m}$ and $L=1.0 \mathrm{~m}$. The inlet velocity and temperature were respectively $u_{\text {in }}=1.0 \mathrm{~m} / \mathrm{s}$ and $T_{f, \text { in }}=300 \mathrm{~K}$. A comparison between the two cases in Figure 1 was made on the basis of a specified total quantity of heat and the imposed heat flux in case I was $q_{w 1}=5 \times 10^{4} \mathrm{~W} / \mathrm{m}^{2}$ while $q_{w 2}=q_{w 1} R_{1} / R_{2}$ in case II. The wall surfaces were opaque with an emissivity of 1.0. Some dimensionless parameters were introduced as

$$
\begin{gathered}
e=\frac{R_{2}}{R_{1}}, \quad \chi=\frac{x}{L}, \quad \theta=\frac{T-T_{f, i n}}{q_{w} R / \lambda_{s e}} \\
q_{w f}^{*}=\frac{q_{w f}}{q_{w}}, \quad q_{w s}^{*}=\frac{q_{w s}}{q_{w}}, \quad q_{w r}^{*}=\frac{q_{w r}}{q_{w}}
\end{gathered}
$$

where $q_{w}$ denotes the total heat flux at the heating wall; $q_{w}=q_{w f}+q_{w s}+q_{w r}, q_{w f}, q_{w s}, q_{w r}$ are respectively the wall heat fluxes for the fluid phase convection, conduction in the solid phase and radiation transport, and $q_{w} R=q_{w 1} R_{1}=q_{w 2} R_{2}$.

The local total heat transfer coefficient was computed as

$$
h_{l x}=\frac{q_{w}}{T_{w, h}-T_{f, b}}
$$

where $T_{w, h}$ and $T_{f, b}$ are the temperature of the heating wall and the bulk mean fluid temperature of the cross-section, respectively. The local Nusselt number was computed as

$$
N u_{l x}=\frac{h_{l x} \cdot 2\left(R_{2}-R_{1}\right)}{\lambda_{0}}
$$

where $\lambda_{0}$ is the reference thermal conductivity and here it was assumed to be the thermal conductivity of the fluid phase at the inlet temperature.

\subsection{Effect of Thermal Radiation on the Heat Transfer Performance}

The influence of high-temperature thermal radiation on the coupled heat transfer inside a foam filled annulus is discussed first. Figure 5 depicts a comparison between the temperature profiles at $\chi=0.9$ and two conditions considering or neglecting the thermal radiation. The foam morphology parameters were given as a porosity of 0.9 and a pore diameter of $2.5 \mathrm{~mm}$. The results clearly show 
that a large deviation will occur if the thermal radiation is not considered, especially for case I. The maximum temperature deviations $(\delta)$ were $19.5 \%(240 \mathrm{~K})$ and $9.3 \%(112 \mathrm{~K})$ at $\chi=0.9$ for the two cases respectively. Besides, since the volumetric effect of radiation transfer within the foam, the temperature gradient along the radial direction was greatly reduced, as displayed in Figure 5. Thermal radiation promotes the heat transfer from a heating wall to the foam matrix and afterward to the airflow, improving the overall heat transfer.
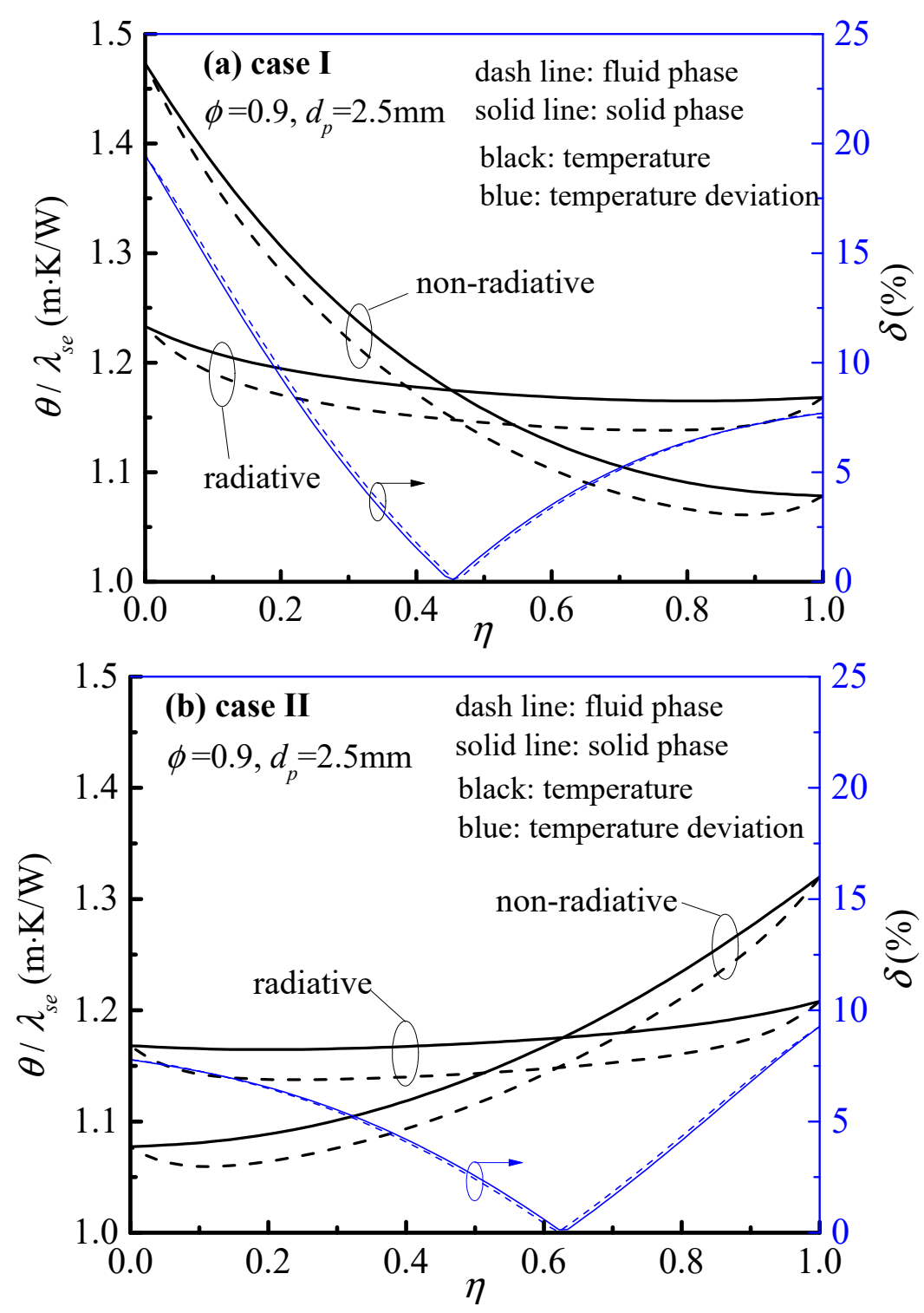

Figure 5. Temperature distribution and deviation for the conditions of considering or neglecting the thermal radiation at $\chi=0.9$ : (a) Case I; (b) Case II.

The high-temperature radiation-conduction coupled heat transfer in the foam matrix resulted in a rapid increment of the solid temperature. Consequently, the temperature difference between the fluid and solid phases became slightly larger than for the condition of neglecting radiation, as illustrated in Figure 6. It can be observed that the maximum value was located near the adiabatic wall. 

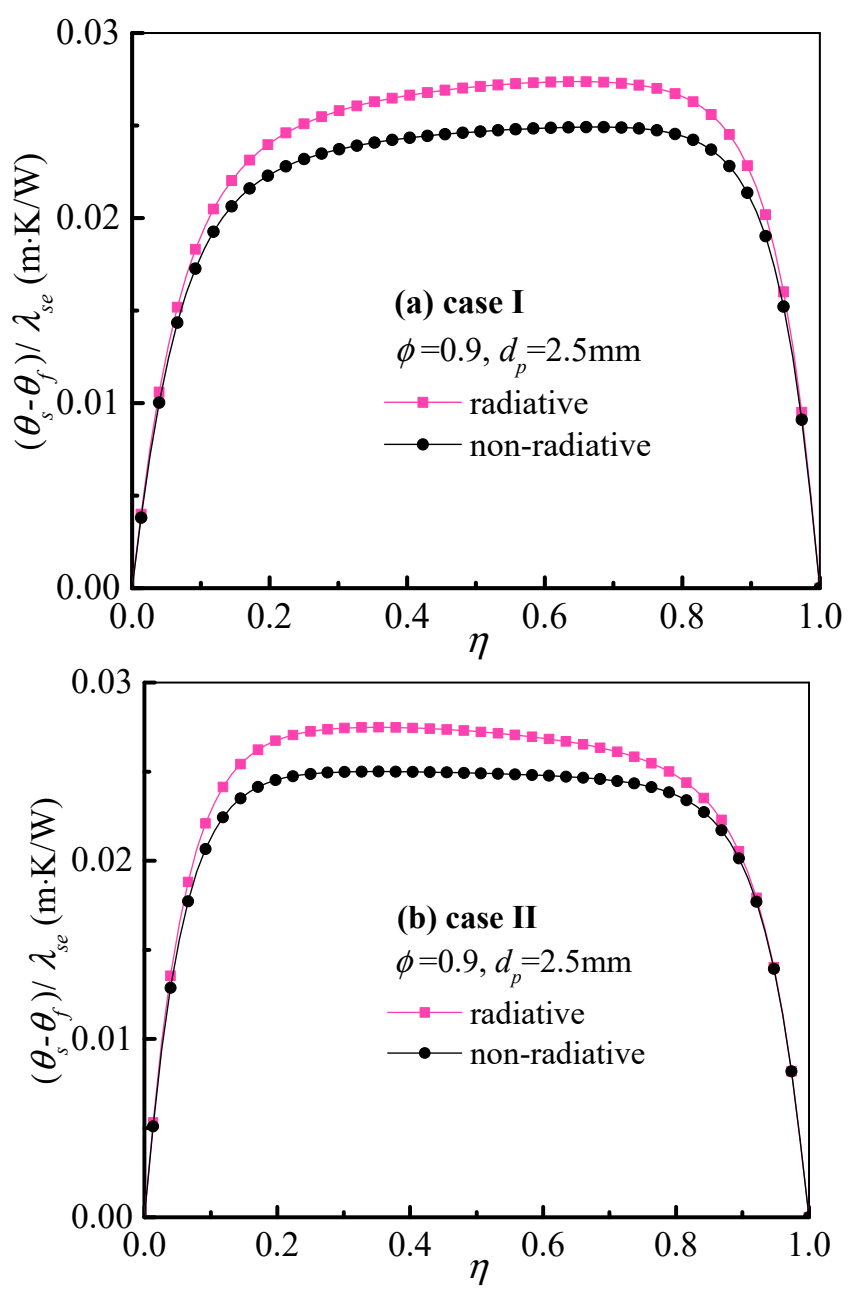

Figure 6. Temperature difference between the fluid and solid phases at a cross-section $\chi=0.9$ : (a) Case I; (b) Case II.

The heat fluxes along with the heating wall are displayed in Figure 7, in order to clarify the relative contributions of radiation transport, solid-matrix conduction, and fluid-flow convention. It is apparent that radiation transport was most significant in the vicinity of the outlet, due to the higher temperature. The maximum proportion of radiation flux reached 69.0 and $66.5 \%$ at the downstream part of the annulus for the two cases respectively. In addition, a limiting interaction between the radiation and conduction was noticed from the variation trends shown in Figure 7. In contrast, the solid conduction was the primary heat transfer mode under the condition of neglecting the thermal radiation, while the conduction flux had a little decrease along the flow direction. 

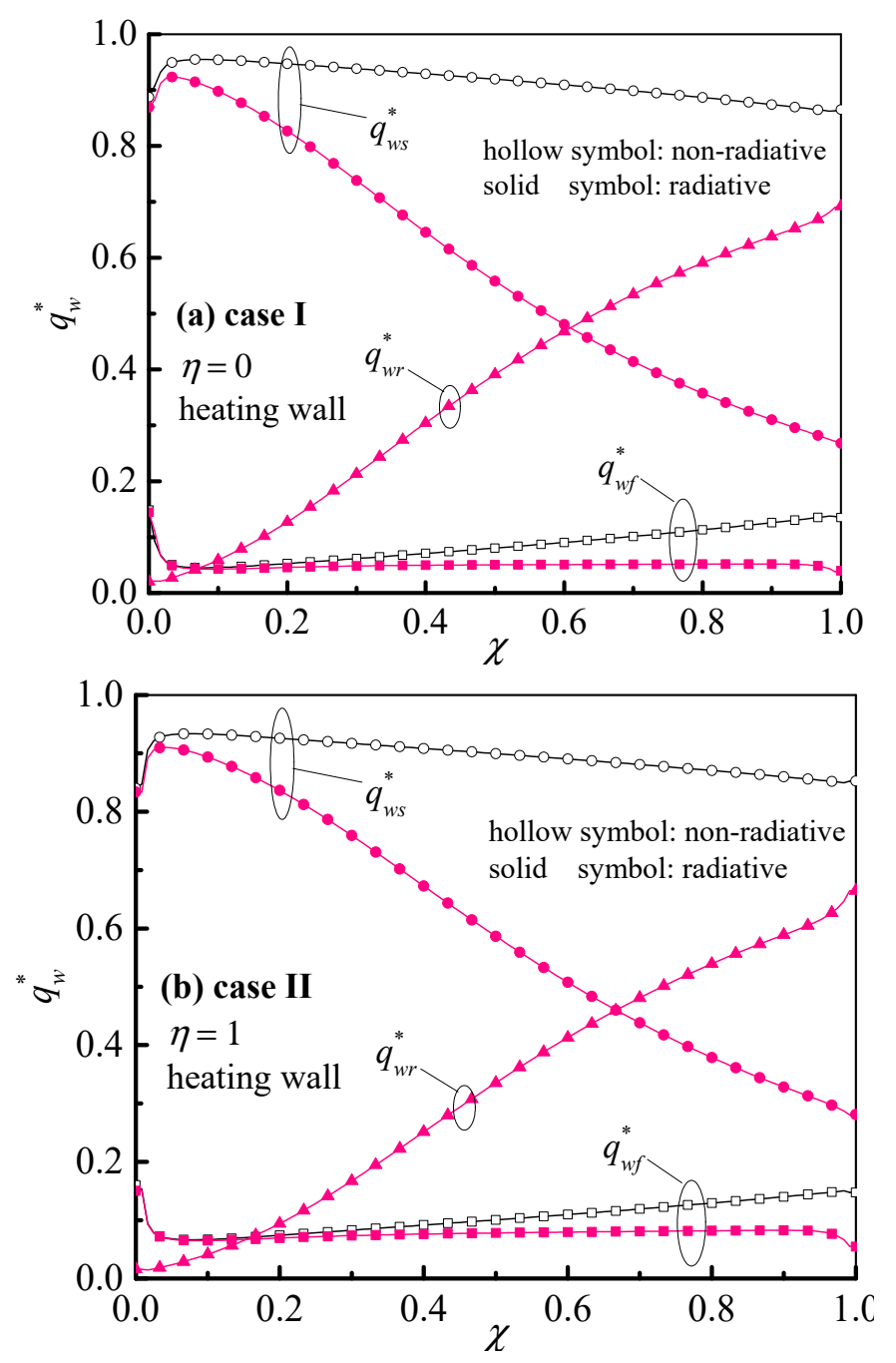

Figure 7. Heat flux at the heating wall along the flow direction: (a) Case I; (b) Case II.

Figure 8 presents the local Nusselt number at the heating wall along the flow direction. The values attained from the radiative simulation were almost larger than those of the non-radiative simulation, while no great difference was observed in the inlet region. This can be attributed to the low temperature in this region that results in little radiation effect. When the radiation effect was neglected, the local Nusselt number gradually achieved an asymptotic value due to the existence of a fully developed state. However, a fully developed temperature profile could not be obtained under consideration of the thermal radiation; accordingly, no such an asymptotic value of the local Nusselt number was determined. This trend is consistent with the phenomena reported in Reference [42]. The radiation improved the local Nusselt number nearly 5 and 4 times near the outlet for case I and II respectively. Besides, the curves indicate that the local Nusselt number in case I was generally larger (21-34\%) than that in case II when considering the radiation heat transfer. 


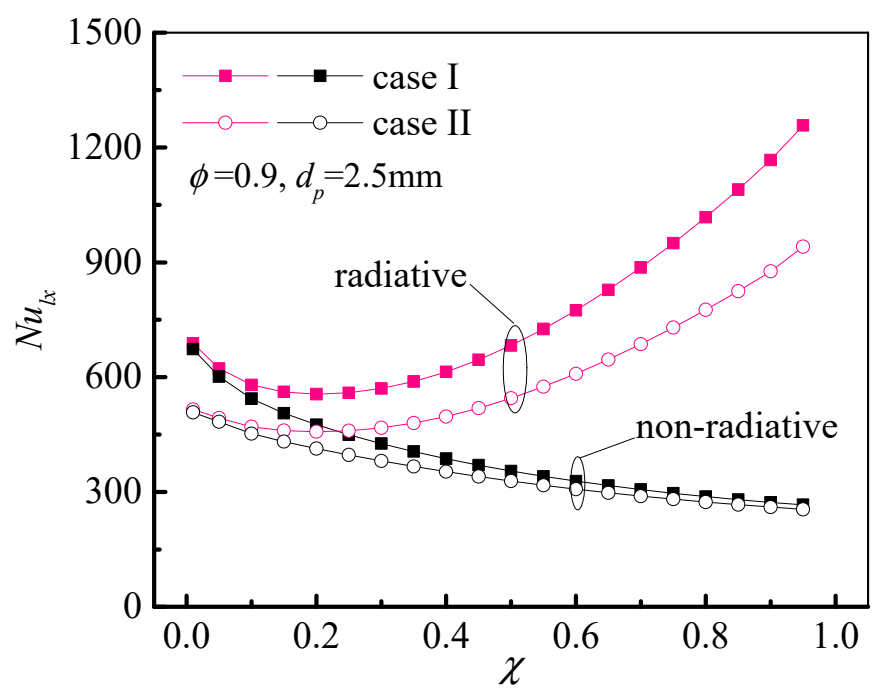

Figure 8. Variation of the local Nusselt number at the heating wall.

\subsection{Parametric Analysis of the Heat Transfer}

The impacts of the foam morphology and the radii ratio of the annulus on the coupled heat transfer in a foam filled annulus were explored. As the trends for the two cases in Figure 1 are similar, the comparisons were mainly given by the results of case I.

As clearly presented in Figure 9a, the solid temperature for the higher porosity was relatively higher, while the temperature difference between the two phases became larger. It was mainly caused by the coupling effect of the three heat transfer modes. As the porosity increased, the fraction of solid matrix decreased, yielding a low thermal capacity and a low effective conductivity. However, the higher porosity has a more sparse pore structure and the penetration of the radiation improved. This can be also reflected by the proportions of the wall heat flux, as presented in Figure $9 \mathrm{~b}$. The proportion of the wall radiation flux had a significant increase, from 28.6 to $63.8 \%$ at $\chi=0.9$, as the porosity increased from 0.7 to 0.9 , while the solid conduction flux decreased from 68.0 to $31.0 \%$. Overall, the thermal radiation dominated the heat transfer process at the rear for the higher porosity. Besides, increasing the porosity reduced the volumetric convection heat transfer coefficient, leading to a larger temperature difference between the fluid and solid phases.

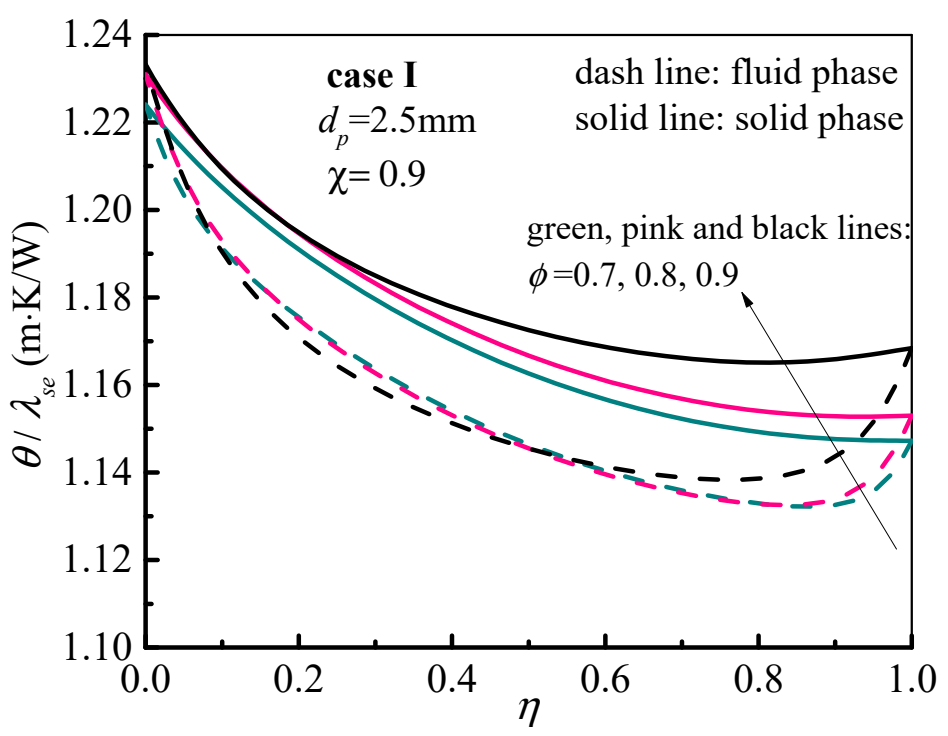

(a)

Figure 9. Cont. 


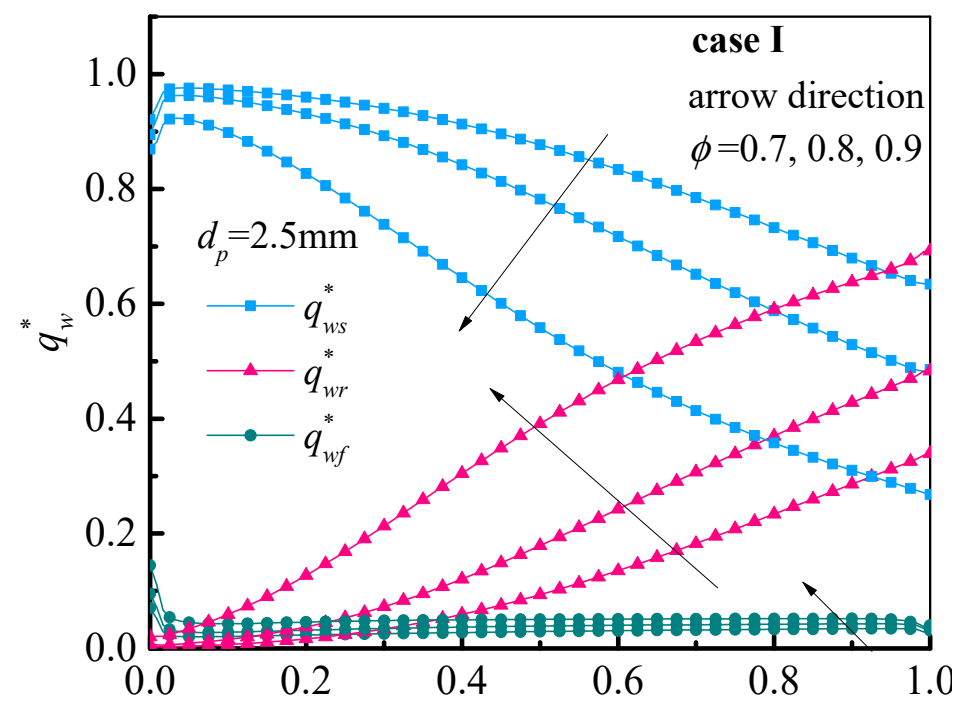

(b)

Figure 9. The effects of the foam porosity on the temperature field and wall heat flux distribution for case I.

(a) The effect on the temperature distribution; (b) the effect on the distribution of the wall heat flux.

Figure 10a demonstrates that the local Nusselt number mostly decreased with the increment of foam porosity. In addition, the minimum value moved towards the annulus inlet, due to the increasing importance of radiation along the flow direction (see Figure $9 \mathrm{~b}$ ). In order to assess the overall heat transfer performance, the parameter $\overline{N u}=\frac{1}{L} \int_{0}^{L} N u_{l x} d x$, defined as the average Nusselt number, with different porosities is depicted in Figure 10b. It can be seen that $\overline{N u}$ gradually decreased as the porosity increased. Thus, even though an increasing porosity improved the penetration of the radiation, the lower porosity yielded a greater heat transfer rate, which can be attributed to the improved conduction in the solid phase. The average Nusselt number decreased from 1457.4 to 704.2 for case I as the porosity increased from 0.65 to 0.95 , or 1197.4 to 516.0 for case II.

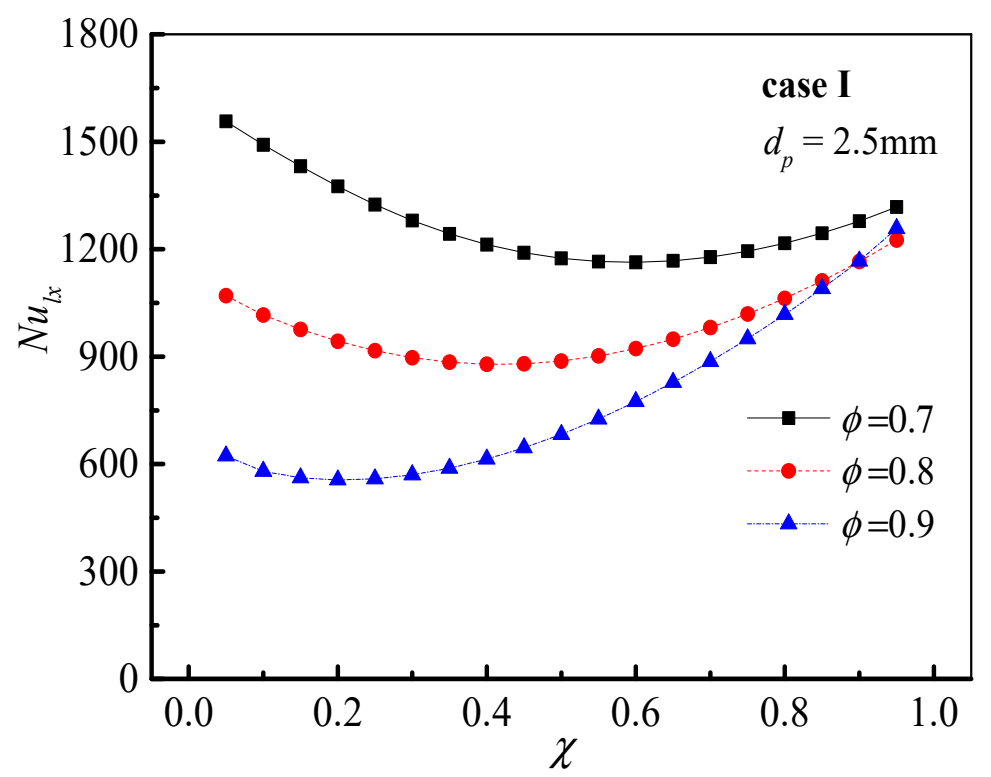

(a)

Figure 10. Cont. 


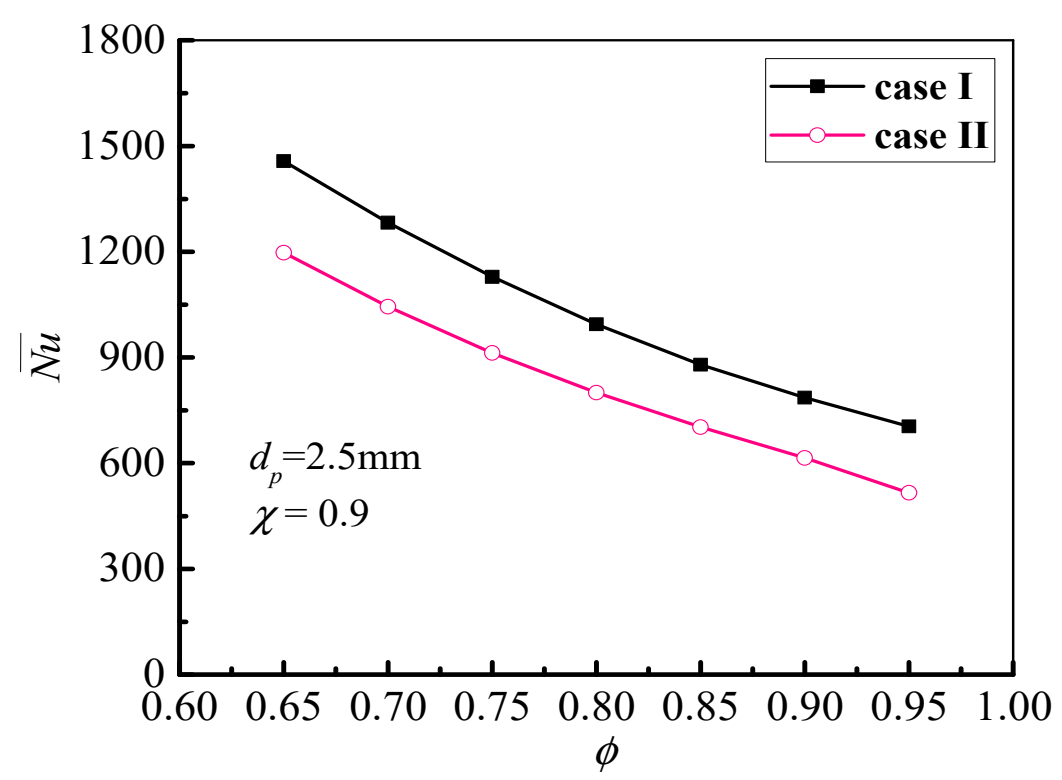

(b)

Figure 10. The effect of the foam porosity on the Nusselt number. (a) The effect on the local Nusselt number distribution; (b) the effect on the average Nusselt number.

Figure 11 presents the influence of pore diameter on the temperature and heat flux distributions with a fixed porosity of 0.9 , while similar trends were observed as those reported in Figure 9. Additionally, the variation in the temperature difference between the fluid and solid phases became more noticeable, as an increased pore diameter reduced the specific surface for heat exchange. The radial temperature distribution was relatively uniform at a large pore diameter due to the enhancement of radiation transport. The proportion of the wall radiation flux increased from 58.2 to $66.6 \%$ for case I at the axial location of $\chi=0.9$.

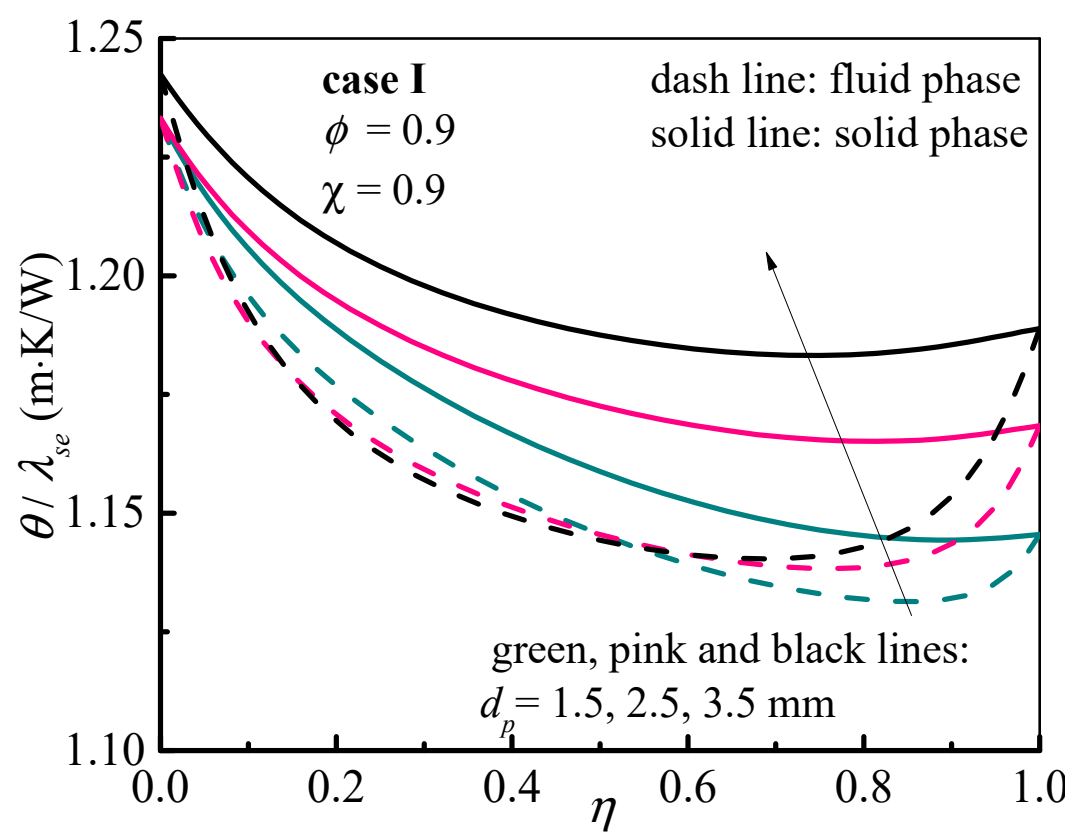

(a)

Figure 11. Cont. 


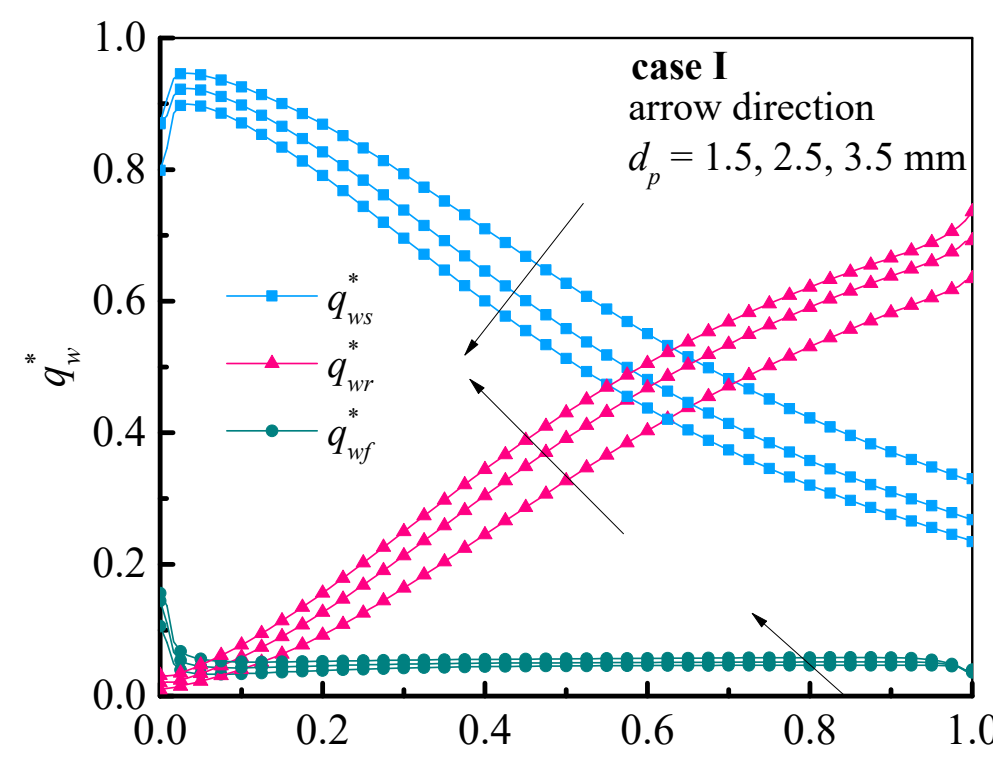

(b)

Figure 11. The effects of the pore diameter on the temperature field and wall heat flux distribution for case I. (a) The effect on the temperature distribution; (b) the effect on the distribution of the wall heat flux.

Figure 12 shows the impact of pore diameter on the Nusselt number. In general, the local Nusselt number had no great change versus the pore diameter, except in the vicinity of the inlet. As the conduction dominated this region and the fluid temperature increased quickly and uniformly for a small pore diameter, which holds a larger volumetric heat transfer coefficient, the temperature between the fluid and heating wall became small. At the rear of the annulus, a non-monotonic change with pore diameter was noticed. Besides, the average Nusselt number also exhibited a non-monotonic variation, with the maximum located at a pore diameter of $2.0 \mathrm{~mm}$ and $1.5 \mathrm{~mm}$ for cases I and II, respectively. For the largest pore diameter, here $(3.5 \mathrm{~mm})$, the predicted average Nusselt number for case I was $40.5 \%$ higher than that of case II.

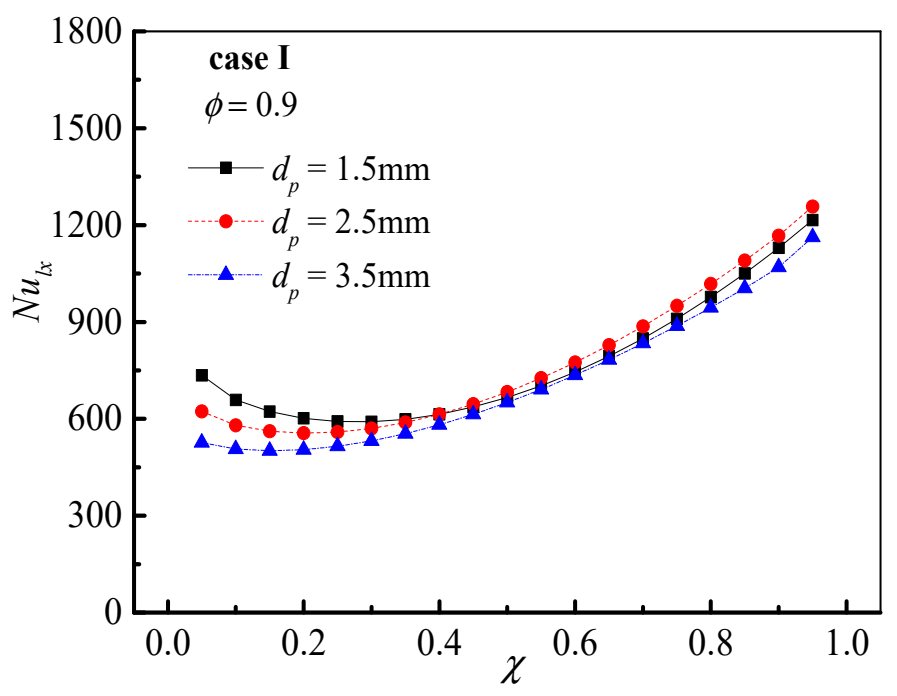

(a)

Figure 12. Cont. 


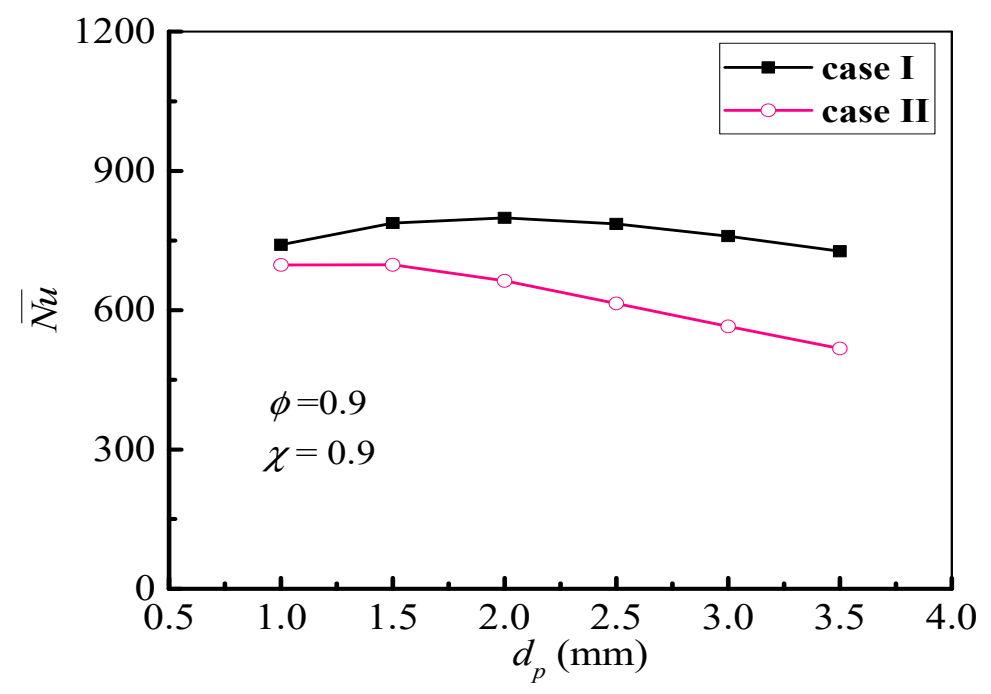

(b)

Figure 12. The effect of the pore diameter on the Nusselt number. (a) The effect on the local Nusselt number distribution; (b) the effect on the average Nusselt number.

The temperature and heat flux distributions with different radii ratios for the foam filled annulus are provided in Figure 13, while the radius of the inner cylinder was fixed at $0.02 \mathrm{~m}$ under the conditions of $\phi=0.9$ and $d_{p}=2.5 \mathrm{~mm}$. It can be clearly seen that both the fluid and solid temperatures descended sharply as the radii ratio ascended. Figure $13 \mathrm{~b}$ reveals that the solid conduction played an important role at the rear for the large radii ratios, while the radiation flux decreased quickly. The trends were quite different from those for the effects of foam porosity and pore diameter.

From Figure 14a, it is apparent that the distribution of the local Nusselt number along with the heating wall became relatively even with the increment of the radii ratio. The radiation effect became small as the radii ratio increased and the solid conduction dominated the heat transfer, especially in the inlet zone (See Figure 13). In addition, the hydraulic diameter ascended as the radii ratio increased, as well as the Reynolds number, the local Nusselt number held a large value in the inlet domain, owing to the entrance effect and the relatively thin thermal boundary layer. The change of the average Nusselt versus radii ratio is displayed in Figure 14b. With an increase in the radii ratio, the average Nusselt number gradually increased after reaching a minimum value. The minimum occurred at a radii ratio of 2.25 and 2.0 respectively for case I and case II. For a small radii ratio, the radiation effect was more significant, as presented in Figure 13, which enhanced the overall heat transfer, especially downstream due to the high temperature. As the radii ratio increased, the radiation effect became remarkably weak. The local Nusselt number in the inlet zone increased gradually while decreasing considerably at the rear, leading to a slight reduction in the average Nusselt number. Furthermore, with further an increasing radii ratio of the annulus, the high local Nusselt number in the entrance zone, due to a high Reynolds number, led to a relative increase in the average Nusselt number. 


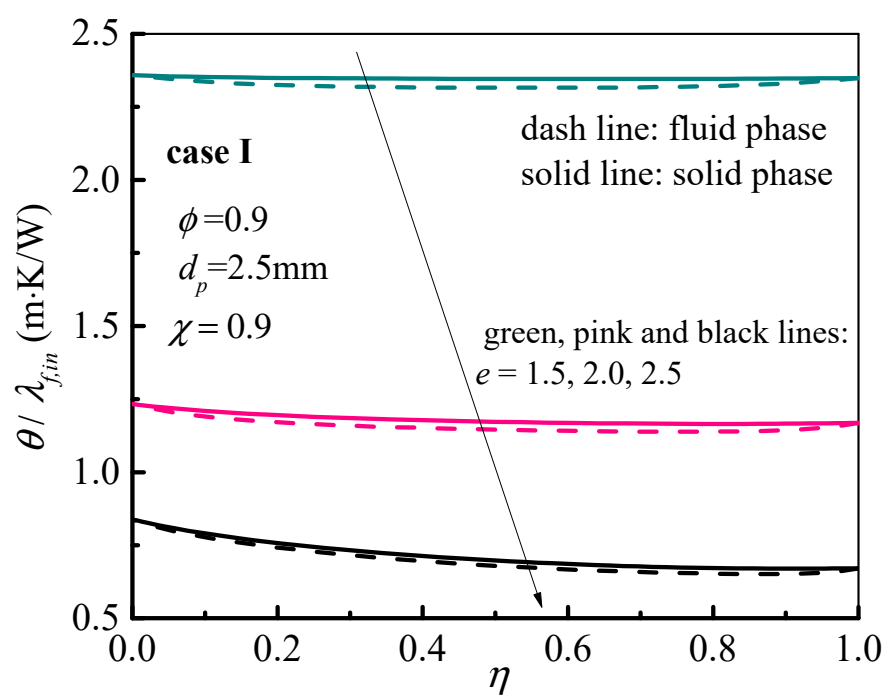

(a)

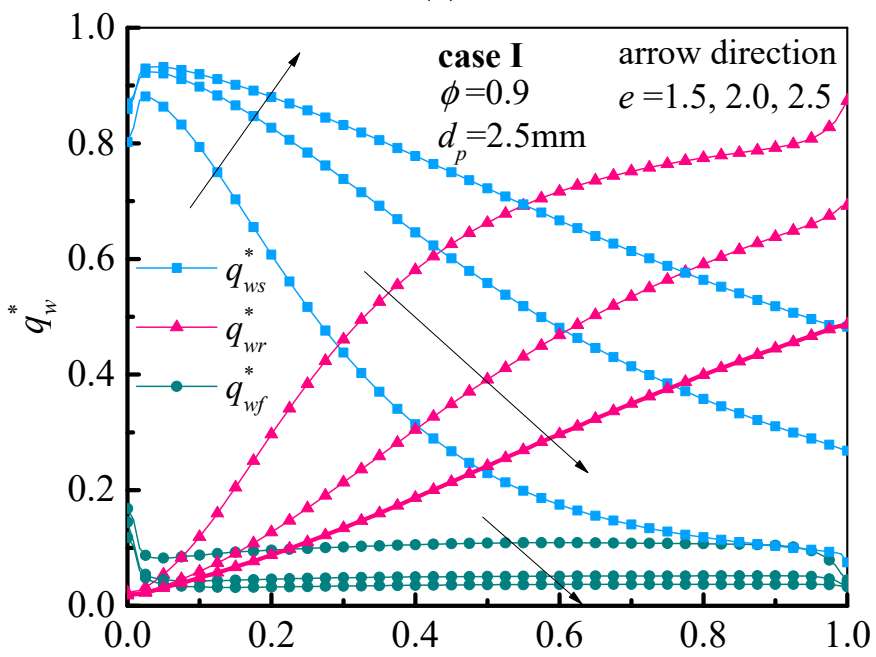

(b)

Figure 13. The effects of the radii ratio on the temperature field and the wall heat flux distribution for case I. (a) The effect on the temperature distribution; (b) the effect on the distribution of the wall heat flux.

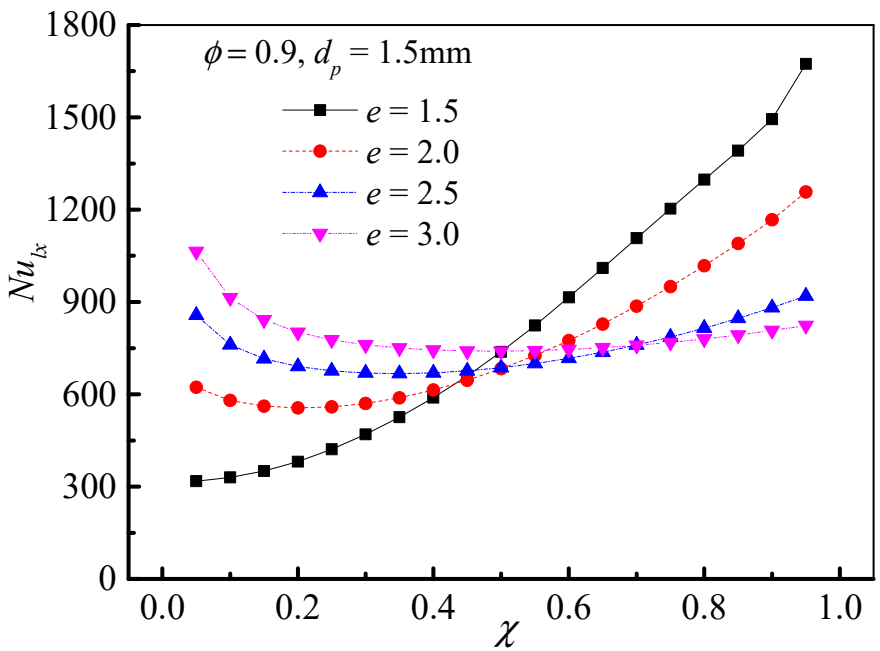

(a)

Figure 14. Cont. 


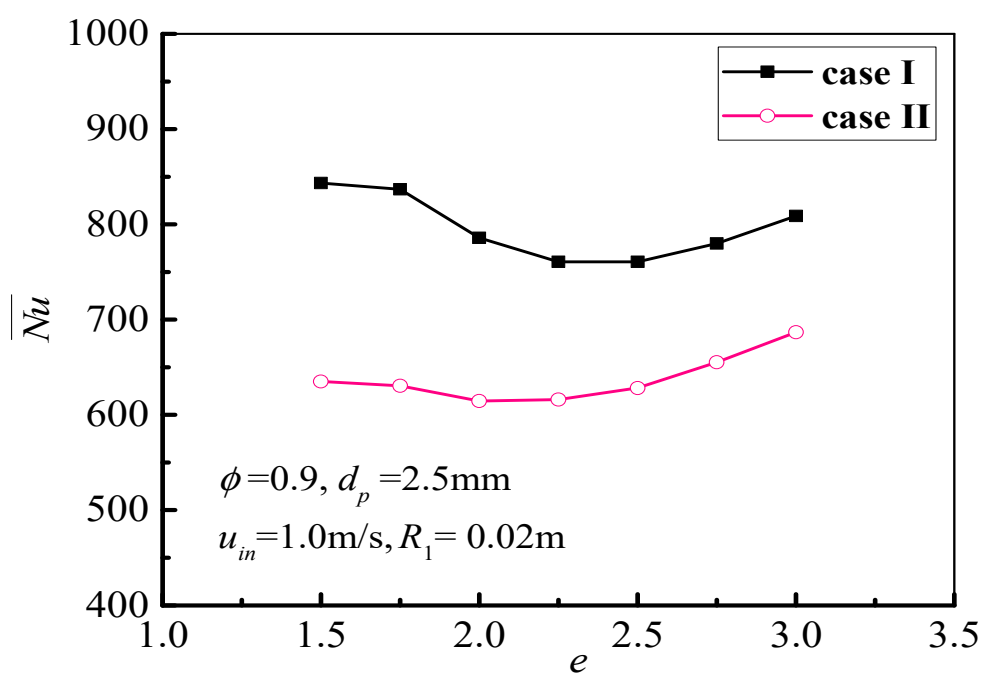

(b)

Figure 14. The effect of the radii ratio of the annulus on the Nusselt number. (a) The effect on the local Nusselt number distribution; (b) the effect on the average Nusselt number.

\section{Conclusions}

In this study, a numerical investigation has been conducted on the radiation-convection coupled heat transfer in an open-cell foam filled annulus for two thermal boundary conditions (cases I and II, in Figure 1). The LTNE model, along with the P1 approximation, was employed for the energy transport within the foam. Parametric simulations were implemented to develop basic information for understanding the effects of key factors on the heat transfer performance of such systems. The main conclusions are drawn as follows:

(1) Thermal radiation strongly affected high-temperature energy transport in a foam filled annulus. Ignoring the thermal radiation led to a significant deviation in predicting the temperature and local Nusselt number, nearly $20 \%$ and $400 \%$ were found.

(2) Limiting interactions between radiation transport and solid conduction were observed, while radiation became predominant by increasing the porosity and pore diameter and decreasing the radii ratio of the annulus.

(3) The porosity and annulus radii ratio had a great effect on the distribution of the local Nusselt number along the flow direction, while the effect of pore diameter was not conspicuous. The average Nusselt number gradually decreased as the porosity increased, whereas it presented a non-monotonic variation with pore diameter and radii ratio.

(4) The difference in the average Nusselt number for the two cases increased as the pore diameter increased, with a maximum of $40.5 \%$, while no great change with the porosity and radii ratio was observed. However, the average Nusselt number was always higher for case I, which presented a better performance under the same operating conditions.

Author Contributions: The idea and methodology were proposed by X.X., the numerical work and manuscript writing were done by X.C. and C.S., and data analysis and paper improvement are done by R.L.

Funding: This work is supported by the National Natural Science Foundation of China (No. 51776053, No. 51536001) and the China Postdoctoral Science Foundation (No. 2018M630350).

Conflicts of Interest: The authors declare no conflict of interest. 


\section{Nomenclature}

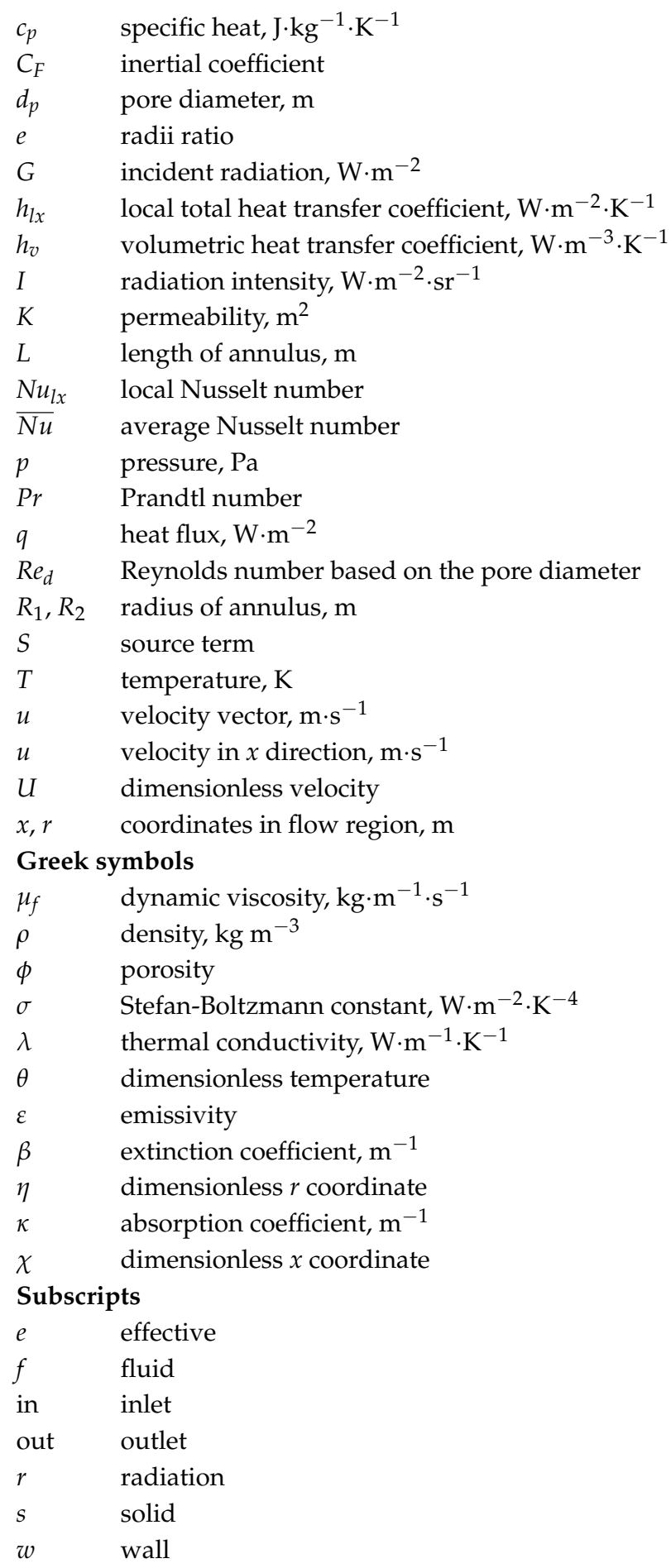

\section{References}

1. Liu, D.; Li, Q.; Xuan, Y.M. Reticulated porous volumetric solar receiver designs guided by normal absorptance and hemispherical volumetric emittance investigations. Int. J. Heat Mass Transf. 2017, 114, 1067-1071. [CrossRef]

2. Chen, X.; Wang, F.Q.; Han, Y.F.; Yu, R.T.; Cheng, Z.M. Thermochemical storage analysis of the dry reforming of methane in foam solar reactor. Energy Convers. Manag. 2018, 158, 489-498. [CrossRef] 
3. Gao, H.B.; Feng, X.B.; Qu, Z.G. Combustion in a hybrid porous burner packed with alumina pellets and silicon carbide foams with a gap. J. Energy Eng. ASCE 2017, 143, 04017032. [CrossRef]

4. Akbarnejad, S.; Saffari Pour, M.; Jonsson, L.T.I.; Jönsson, P.G. Effect of fluid bypassing on the experimentally obtained Darcy and Non-Darcy permeability parameters of ceramic foam filters. Metall. Mater. Trans. B Proc. Metall. Mater. Proc. Sci. 2017, 48, 197-207. [CrossRef]

5. Iasiello, M.; Cunsolo, S.; Oliviero, M.; Harris, W.M.; Bianco, N.; Chiu, W.K.S.; Naso, V. Numerical analysis of heat transfer and pressure drop in metal foams for different morphological models. J. Heat Transf. Trans. ASME 2014, 136, 112601. [CrossRef]

6. Vafai, K. Handbook of Porous Media; CRC Press: Boca Raton, FL, USA, 2005.

7. Yang, K.; Vafai, K. Transient aspects of heat flux bifurcation in porous media: An exact solution. J. Heat Transf. Trans. ASME 2011, 133, 052602. [CrossRef]

8. Mahmoudi, Y. Effect of thermal radiation on temperature differential in a porous medium under local thermal non-equilibrium condition. Int. J. Heat Mass Transf. 2014, 76, 105-121. [CrossRef]

9. Dehghan, M.; Valipour, M.S.; Keshmiri, A.; Saedodin, S.; Shokri, N. On the thermally developing forced convection through a porous material under the local thermal non-equilibrium condition: An analytical study. Int. J. Heat Mass Transf. 2016, 92, 815-823. [CrossRef]

10. Chen, X.; Xia, X.L.; Sun, C.; Yan, X.W. Transient thermal analysis of the coupled radiative and convective heat transfer in a porous filled tube exchanger at high temperatures. Int. J. Heat Mass Transf. 2017, 108, 2472-2480. [CrossRef]

11. Wang, H.; Guo, L. Experimental investigation on pressure drop and heat transfer in metal foam filled tubes under convective boundary condition. Chem. Eng. Sci. 2016, 155, 438-448. [CrossRef]

12. Xu, Z.G.; Qin, J.; Zhou, X.; Xu, H.J. Forced convective heat transfer of tubes sintered with partially-filled gradient metal foams (GMFs) considering local thermal non-equilibrium effect. Appl. Therm. Eng. 2018, 137, 101-111. [CrossRef]

13. Chumpia, A.; Hooman, K. Performance evaluation of single tubular aluminium foam heat exchangers. Appl. Therm. Eng. 2014, 66, 266-273. [CrossRef]

14. Dixit, T.; Ghosh, I. Geometric mean of fin efficiency and effectiveness: A parameter to determine optimum length of open-cell metal foam used as extended heat transfer surface. J. Heat Transf. Trans. ASME 2017, 139, 072003. [CrossRef]

15. Ahmed, H.E.; Ahmed, M.I. Thermal performance of annulus with its applications: A review. Renew. Sustain. Energy Rev. 2017, 71, 170-190. [CrossRef]

16. Li, S.; Chen, Y.; Sun, Z. Numerical simulation and optimization of the melting process of phase change material inside horizontal annulus. Energies 2017, 10, 1249.

17. Cheng, P.; Hsu, C.T. Fully-developed, forced convective flow through an annular packed-sphere bed with wall effects. Int. J. Heat Mass Transf. 1986, 29, 1843-1853. [CrossRef]

18. Chikh, S.; Boumedien, A.; Bouhadef, K.; Lauriat, G. Analytical solution of non-Darcian forced convection in an annular duct partially filled with a porous medium. Int. J. Heat Mass Transf. 1995, 38, 1543-1551. [CrossRef]

19. Noh, J.S.; Lee, K.B.; Lee, C.G. Pressure loss and forced convective heat transfer in an annulus filled with aluminum foam. Int. Commun. Heat Mass Transf. 2006, 33, 434-444. [CrossRef]

20. Chikh, S.; Allouache, N. Optimal performance of an annular heat exchanger with a porous insert for a turbulent flow. Appl. Therm. Eng. 2016, 104, 222-230. [CrossRef]

21. Benmerkhi, M.; Afrid, M.; Groulx, D. Thermally developing forced convection in a metal foam-filled elliptic annulus. Int. J. Heat Mass Transf. 2016, 97, 253-269. [CrossRef]

22. Milani Shirvan, K.; Mirzakhanlari, S.; Kalogirou, S.A.; Öztop, H.F.; Mamourian, M. Heat transfer and sensitivity analysis in a double pipe heat exchanger filled with porous medium. Int. J. Therm. Sci. 2017, 121, 124-137. [CrossRef]

23. Kuznetsov, A.V. Analysis of a non-thermal equilibrium fluid flow in a concentric tube annulus filled with a porous medium. Int. Commun. Heat Mass Transf. 1996, 23, 929-938. [CrossRef]

24. Zhao, C.Y.; Lu, W.; Tassou, S.A. Thermal analysis on metal-foam filled heat exchangers. Part II: Tube heat exchangers. Int. J. Heat Mass Transf. 2006, 49, 2762-2770. [CrossRef]

25. Yang, C.; Kuwahara, F.; Liu, W.; Nakayama, A. Thermal non-equilibrium forced convective flow in an annulus filled with a porous medium. Open Transp. Phenom. J. 2011, 3, 31-39. [CrossRef] 
26. Qu, Z.G.; Xu, H.J.; Tao, W.Q. Fully developed forced convective heat transfer in an annulus partially filled with metallic foams: An analytical solution. Int. J. Heat Mass Transf. 2012, 55, 7508-7519. [CrossRef]

27. Wang, K.; Tavakkoli, F.; Vafai, K. Analysis of gaseous slip flow in a porous micro-annulus under local thermal non-equilibrium condition-An exact solution. Int. J. Heat Mass Transf. 2015, 89, 1331-1341. [CrossRef]

28. Xu, H.J.; Zhao, C.Y.; Vafai, K. Analytical study of flow and heat transfer in an annular porous medium subject to asymmetrical heat fluxes. Heat Mass Transf. 2017, 53, 2663-2676. [CrossRef]

29. Xu, H.J. Convective heat transfer in a porous-medium micro-annulus with effects of the boundary slip and the heat-flux asymmetry: An exact solution. Int. J. Therm. Sci. 2017, 120, 337-353. [CrossRef]

30. Orihuela, M.P.; Anuarb, F.S.; Abdib, I.A.; Odabaee, M.; Hooman, K. Thermohydraulics of a metal foam-filled annulus. Int. J. Heat Mass Transf. 2018, 117, 95-106. [CrossRef]

31. Chen, X.; Xia, X.L.; Meng, X.L.; Dong, X.H. Thermal performance analysis on a volumetric solar receiver with double-layer ceramic foam. Energy Convers. Manag. 2015, 97, 282-289. [CrossRef]

32. Hansen, G.; Nass, E.; Kristjansson, K. Analysis of a vertical flat heat pipe using potassium working fluid and a wick of compressed nickel foam. Energies 2016, 9, 170. [CrossRef]

33. Banerjee, A.; Bala Chandran, R.; Davidson, J.H. Experimental investigation of a reticulated porous alumina heat exchanger for high temperature gas heat recovery. Appl. Therm. Eng. 2015, 75, 889-895. [CrossRef]

34. Schuetz, M.A.; Glicksman, L.R. A basic study of heat transfer through foam insulation. J. Cell. Plast. 1984, 20, 114-121. [CrossRef]

35. Hischier, I.; Hess, D.; Lipiński, W.; Modest, M.; Steinfeld, A. Heat transfer analysis of a novel pressurized air receiver for concentrated solar power via combined cycles. J. Therm. Sci. Eng. Appl. 2009, 1, 041002. [CrossRef]

36. Tseng, C.C.; Sikorski, R.L.; Viskanta, R.; Chen, M.Y. Effect of foam properties on heat transfer in high temperature open-cell foam inserts. J. Am. Ceram. Soc. 2012, 95, 2015-2021. [CrossRef]

37. Modest, M.F. Radiative Heat Transfer, 3rd ed.; Academic Press: San Diego, CA, USA, 2013.

38. Wang, P.; Vafai, K.; Liu, D.Y.; Xu, C. Analysis of collimated irradiation under local thermal non-equilibrium condition in a packed bed. Int. J. Heat Mass Transf. 2015, 80, 789-801. [CrossRef]

39. Wu, Z.; Caliot, C.; Flamant, G.; Wang, Z.F. Coupled radiation and flow modeling in ceramic foam volumetric solar air receivers. Sol. Energy 2011, 85, 2374-2385. [CrossRef]

40. Hischier, I.; Leumann, P.; Steinfeld, A. Experimental and numerical analyses of a pressurized air receiver for solar-driven gas turbines. J. Sol. Energy Eng. Trans. ASME 2012, 134, 021003. [CrossRef]

41. Calmidi, V.V.; Mahajan, R.L. Forced convection in high porosity metal foams. J. Heat Transf. Trans. ASME 2000, 122, 557-565. [CrossRef]

42. Talukdar, P.; Mishra, S.C.; Trimis, D.; Durst, F. Combined radiation and convection heat transfer in a porous channel bounded by isothermal parallel plates. Int. J. Heat Mass Transf. 2004, 47, 1001-1013. [CrossRef] 